\title{
La vida secreta de un pintor neoclásico: Roger y Angélica en Balneario de Adolfo Couve
}

The Secret Life of a Neoclassical Painter: Roger and Angélica in Balneario by Adolfo Couve Vida secreta de um pintor neoclássico: Roger e Angélica em Balneario de Adolfo Couve

\section{Felipe Toro}

GEORGETOWN UNIVERSITY, ESTADOS UNIDOS

Estudiante doctoral de literatura hispanoamericana en Georgetown University, Estados Unidos. Magíster en Literatura por la Universidad de Chile, Santiago. Investiga cruces trasantlánticos en narrativas del Cono Sur. Sobre Adolfo Couve, ha publicado "Continuidad de los parques: lectura viñamarina de El picadero" (Revista Laboratorio, 2014), "Una mirada a los niños reyes de Adolfo Couve" (Anales de Literatura Chilena, 2014), "Una pieza secreta: juegos y juguetes en la narrativa de Adolfo Couve" (Revista Chilena de Literatura, 2013) y, en coautoría con Pablo Chiuminatto, "El ejercicio de la corrección: lectura del manuscrito de La lección de pintura" (Literatura y Lingüística, 2014). Correo electrónico: felipetorofranco@gmail.com

\section{Pablo Chiuminatto}

PONTIFICIA UNIVERSIDAD CATÓLICA DE CHILE, CHILE

Profesor del Departamento de Literatura de la Pontificia Universidad Católica de Chile,

Santiago. Doctor en filosofía por la Universidad de Chile. Ha desarrollado investigación y docencia en torno a la literatura comparada; los diálogos entre la literatura y las artes visuales; las humanidades digitales, y las tecnologías de la educación. Sus ensayos interdisciplinarios circulan en revistas nacionales e internacionales. Entre sus últimos libros se encuentran Diálogos para una nueva escuela en Chile (2016; en coautoría con Miguel Naussbaum), René Descartes, el método de las figuras: imaginario visual e ilustración científica (Orjikh, 2013) y La filosofía de la decoración (Orjikh, 2012; en coautoría con B. Alberdi). Correo electrónico: pchiuminatto@uc.cl

Artículo de reflexión

Documento accesible en línea desde la siguiente dirección: http://revistas.javeriana.edu.co doi:10.11144/Javeriana.cl21-42.vspr 


\section{Resumen}

Por medio de la lectura de Balneario de Adolfo Couve - relato breve que aborda las fantasías eróticas de Angélica Bow, vieja aristócrata que anhela el encuentro con jóvenes de clases bajas en un balneario popular de Chile-, intentamos despejar la referencia de la poética de Couve a la escuela neoclásica, y en especial su apelación a la herencia pictórica de Jean-Auguste Dominique Ingres. Así, proponemos que en Balneario Couve reescribe la famosa pintura de Ingres Roger liberando a Angélica - a su vez basada en el canto $\mathrm{X}$ del Orlando furioso de Ariostoactualizando un debate de larga data entre imagen y escritura en un escenario provinciano.

Palabras clave: Adolfo Couve; Ingres; Ariosto; crítica genética

\section{Abstract}

Through the reading of Adolfo

Couve's Balneario - a brief story that deals with the erotic fantasies of Angelica Bow, an old aristocrat who longs for encounters with lower-class youths in a popular resort in Chile - we attempt to clear the reference of Couve's poetics to the neoclassical school, and particularly, his appeal to the pictorial heritage of Jean-Auguste Dominique Ingres. Thus, we suggest that in Balneario, Couve re-writes Ingres' famous painting Roger Freeing Angelica, which in turn is based on Canto $\mathrm{X}$ of Orlando Furioso by Ariosto, thus updating a long-standing debate between image and writing on a provincial stage.

Keywords: Adolfo Couve; Ingres; Ariosto; genetic criticism

\section{Resumo}

Por meio da leitura de Balneario de Adolfo Couve - relato breve que aborda as fantasías eróticas de Angélica Bow, velha aristócrata que anseia para o encontro com jovens de camadas baixas em um balneário popular do Chiletentamos descobrir a referência da poética de Couve à escola neoclássica, e especialmente a sua apelação à herança pictórica de Jean-Auguste Dominique Ingres. Assim, propomos que em Balneario, Couve reescreve a famosa pintura de Ingres Roger liberando a Angélica (1819)

- que por sua vez está baseada no canto X do Orlando furioso de Ariosto - a atualizar um longo debate entre imagem e escrita em um cenário provinciano.

Palavras-chave: Adolfo Couve; Ingres; Ariosto; crítica genêtica 
UNA DE LAS tantas perplejidades que nos guarda la lectura de Adolfo Couve es el misterio de su caprichosa biblioteca, de la cartografía de referencias que sustenta existencial y culturalmente sus relatos (capaces de situar a Apolo en el balneario de Cartagena, a Gustave Flaubert junto al pintor chileno Pablo Burchard, o imágenes de Rembrandt junto a ilustraciones de Coré). El misterio de nombres en los que late una onomástica tan privada como enigmática: baste recordar, por ejemplo, al teniente Condarco, de El picadero (1974); a Francisco Chabry, de La copia de yeso (1989), o al mismísimo Camondo, de La comedia del arte (1995). Condarco, en quien resuena el segundo apellido del primer alcalde de la ciudad de Viña del Mar, es creado por Couve para hacerlo habitar su nouvelle sobre la maldición de la familia Vergara y su casa-quinta. Francisco Chabry, cuyos nombre y apellido pertenecen a un "distinguido horticultor francés [del siglo XIX] radicado en Valparaíso" (Greve 396), es transformado por Couve en el narrador decimonónico que gestiona, junto a Raymond Monvoisin, el traslado a Chile de las copias de yeso para el Museo de Bellas Artes (¿acaso el homenaje a un antepasado, a uno de sus venerados mayores? ["Prólogo" 7]). Por último, el Conde Isaac Camondo (1851-1911), uno de los primeros coleccionistas de la obra de Cézanne - artista predilecto de Couve - es transformado en un pintor en crisis (Roquebert 226). Qué duda cabe, las coordenadas del imaginario de Couve - su biblioteca, sus álbumes familiares, sus almanaques viejos - retoman personajes de la historia nacional al borde del olvido, pero que también nos invitan a cruzar al otro lado del Atlántico, a la nostalgia por una Francia decimonónica desfigurada por la distancia y la migrancia (Valdés 14).

Se configura una singular y enigmática biblioteca en la que, como Borges invitaba a hacer en "El escritor argentino y la tradición", se anudan la afiliación antojadiza, el juicio rotundo y la libertad de quien se apropia de los materiales de la cultura europea sin superstición. La libertad de quien a la vez está y no está, con un pie en la letra y otro en la imagen, con un pie en Francia y otro en Chile, con un pie en Cartagena y otro en Santiago, uno en el siglo XIX - el enunciado - y otro en el XX - la enunciación-. Así, cuando creemos fijarlo en el encuadre, Couve se escapa metonímicamente, se escabulle. Otro tanto sucede con el catálogo visual de sus referencias, sus fatigosos esfuerzos por traducir la experiencia pictórica a la escritura, en un ejercicio condenado a la desesperación estilística. ${ }^{1}$ Desconcierta, viniendo

1 Sobre la frustración inherente a todo ejercicio ecfrástico, dice Murray Krieger: "The ekphrastic aspiration in the poet and the reader must come to terms with two opposed impulses, two 
de un pintor que reconoce la influencia de la obra de Cézanne, la confesa apelación de su narrativa a "[t] estimonios convincentes como el de David e Ingres, o sea una escuela, la neoclásica, quizá un tanto escenográfica, pero cargada de poesía, ingenuidad y afán de organizar un mundo autónomo" (Couve, "Prólogo" 8). Tanto así que, de acuerdo con sus manuscritos, antes había considerado titular la novela La lección de pintura (1979) como "La vida secreta de un pintor neoclásico". Así mismo, Jean-August Dominique Ingres (1780-1867) y el personaje de Augusto Medrano comparten más de una seña de identidad en ese texto. Quizá, siguiendo a Baudelaire, también podríamos decir de Couve: "Les ouvres de M. Ingres, qui sont le résultat d'une attention excessive, veulent une attention égale pour être comprises. Filles de la doleur, elles engendrent la doleur" ("Salon de $1846 " 631$, énfasis nuestro).

De largo aliento, la persistencia de las menciones a Ingres en Couve nos despista del mismo modo que el medallón oblicuo a los pies de Los embajadores (1533), de Hans Holbein: aunque estén aparentemente fuera de lugar, no podemos quitarles la vista y dejar de preguntarnos qué fantasías están en juego detrás de una ars poetica como esta; qué hilos mueven saltos tan improbables para nuestros horizontes de expectativas. De hecho, se trata literalmente de una búsqueda situada en otro horizonte visual, pero también transatlántico; en una cartografía de referencias migrantes. Ya ha reparado en ello Adriana Valdés en su magnífico prólogo a Cuando pienso en mi falta de cabeza (2000): "Sus lectores convendrán conmigo en que sus relatos dan una impresión totalmente diferente a la de estos grandilocuentes pintores[, David e Ingres], y que en esta diferencia vuelve la idea de 'la lectura al sesgo' de sus declaraciones sobre el realismo" (15). Quisiéramos, en este sentido, que este ensayo fuera tomado como un esfuerzo por retomar esa lectura al sesgo capaz de dejar entrever la calavera en el medallón del cuadro de Holbein (que, para el caso de Couve, aparece bajo la forma de un registro de citas). Se trata de un registro que, por lo demás, hace que Couve se mueva en la narrativa chilena como un extranjero; un advenedizo que se tutea con Dante, y de ahí la marca de extranjería de buena parte de sus personajes sin sustento: Camondo y

opposed feelings, about language: one is exhilarated by the notion of ekphrasis and one is exasperated by it $[\ldots]$. The first asks for language -in spite of its arbitrary character and its temporality - to freeze itself into a spatial form. Yet it retains an awareness of the incapacity of words to come altogether at an instant (tout à coup) [...]. Their incapacity is precisely what is to be emphasized: words cannot have capacity, cannot be capacious, because they have, literally, no space" (10). 
Chabry, amén de sus niños con nostalgias nobiliarias, perdidos en una cité o en la incomprensión artística como destino.

Pero, ¿cómo leer sus afinidades electivas? El imperio de lo visual presente en su literatura es algo que comúnmente se da por hecho, pero que puede convertirse en una tentación reductiva, dada la facilidad con que nos dejamos seducir por sus protagonistas, ellos mismos, muchas veces, pintores de caballete. Y, además, por el problema de convertir una certeza crítica (Couve y la écfrasis, por ejemplo) en una moneda de cambio que nuble el detalle específico, sin reparar en el medallón oblicuo de Los embajadores, en su apropiación maliciosa, criolla, del archivo europeo. No por nada Adriana Valdés caracterizaba su obra como " "[r] ealista' y francesa, por una parte; por otra, inquietante, misteriosa y ferozmente local" (14); y Ariel Dorfman, en lo que es la primera piedra para los estudios de su obra, tempranamente veía en la familia de inmigrantes Méric de sus primeros relatos un anagrama del destino americano: A-méric (86).

La veneración de Couve a "mis ancestros franceses" ("Prólogo" 7) o la aspiración de vislumbrar la escena original situando a Francisco Chabry justo en 1848, puede, quizá, entenderse como la traducción al espacio familiar de un problema crucial para su narrativa: ¿qué hacer con la tradición, cómo recibir la herencia sin ser aplastado por el punto de apoyo? Este sí que es un problema con el que tuvieron que lidiar Jacques-Louis David e Ingres, porque al proponer "la restauración consciente de los presuntos orígenes de la tradición", el neoclasicismo "niega absolutamente el derecho a la guerra contra la tradición [..., amenazando al pintor] con su propia muerte como artista ('donde quiera que hayas estado, allí estará la tradición')" (Bryson 49). Couve superpone su genealogía a la herencia cultural al punto de que el personaje de Chabry es el encargado de traerla de París a Chile en copias de yeso, haciendo que la persistencia de la mirada francesa en sus relatos sucumba al destino trágico del amor. Dar lo que no se tiene a quien no lo necesita: "[m] gustaría que [estas obras literarias] retornaran a su utópico lugar de origen a través de la traducción al francés..." (Couve, "Prólogo" 10); declaración de amor a los antepasados no exenta de desencuentros, porque las cartas que Chabry le escribe desde París a su amada chilena jamás llegan al puerto (La copia de yeso 288) y Chabry desaparece en la angustia. Porque el apego excesivo a la tradición acarrea el peligro de condenar al artista a la repetición; de convertirlo en otra copia de yeso más. Quien lea el manuscrito constatará que en un momento el título tachado de la novela era Francisco Chabry (el hombre de yeso), con el que se anticipa en varios años el malogrado destino del pintor Camondo, protagonista de Cuando pienso en mi falta de cabeza, "el hombre de cera" (435). La literatura de Couve, llena de 
anuncios, se despliega como un solo movimiento hacia su eclipse. Recordemos a Bryson nuevamente, quien declara como un oráculo: "El neoclasicismo es un estilo fatal: tiene una cualidad letal y casi todas sus producciones portan, en algún lugar de su superficie, la marca de la muerte" (51).

Advirtamos a simple vista que la poética de Couve - con la tradición a cuestas - se ha impuesto una tarea desproporcionada de la que dan detallada cuenta sus manuscritos. Allí el narrador ensaya caminos, tentativas sobre cómo retomar la posta, siempre asediado por la sombra de sus precursores; un amor capaz de petrificarlo y del que su obra pictórica tampoco se sustrae ("[e]n todas sus telas se puede reconocer con mayor o menor nitidez el legado de los maestros a partir de los cuales construyó su propia obra" [Campaña 106]). Entre estos criollos papeles de Aspern, el manuscrito del relato breve Balneario (1993) ilumina la soslayada relación que la narrativa de Couve tiene con sus modelos pictóricos confesos (a primera vista, tan lejanos). Este corresponde, además, a un punto de no retorno, al tratarse de la primera vez que su escritura toma posesión - como un rey- del derruido paisaje de la costa de Cartagena. Valga recordar las primeras líneas del manuscrito, después tarjadas, en su párrafo de obertura; palabras enunciadas desde un grácil yo que después abdicará: "Y mientras deambulo por este balneario de Cartagena, juego a ser rey a pensar que en otra vida fui, y me es tan natural pensar que una mañana mi ayo me levantó de madrugada para que me siñeran [sic] la corona" (Manuscrito de Balneario, sin núm.; los autores conservan la ortografía). Lo que sigue después será casi exactamente el comienzo de Balneario como lo conocemos - "Cartagena, el balneario, esa playa sucia, abandonada todos los inviernos, ese escenario, ese deterioro infinito..." (307)—, eso sí, desprovisto para siempre de ese yo, rey de Cartagena, y dotado de una prosa estrictamente impersonal; de un tono elegíaco y desesperado. Da la impresión de que de haber llegado un segundo antes, habríamos encontrado al narrador en el traje de arlequín que después Couve encarnará en La comedia del arte (1995): “...utilizo a mi amaño la primera persona, licencia que antes, por lo general, no me permití" (366).

¿Y qué hay de este rey imaginario de finales del siglo XX chileno? En algo nos recuerda la aventura de Orélie Antoine de Tunens (1781-1862), que se autodenominó rey de la Araucanía - otro francés decimonónico, noble, capaz de unir Arauco con París-, y en algo también evoca nuestras monarquías populares, como el rey de la empanada, el rey del mote con huesillo. Couve, después de todo, está en Cartagena, un balneario originalmente aristocrático de comienzos del siglo XX, que ha sido abandonado por sus propios fundadores. Su mirada en Balneario al veraneo del mundo popular se debate entre la voluptuosidad y el 
rechazo; entre la fascinación por la otredad y la mueca grotesca. Así se pasea por la playa su protagonista Angélica Bow, veterana aristócrata sacada de las antiguas páginas sociales de Cartagena y hoy arrojada a su paradójico presente, como si se tratara de su último solitario vestigio; su última habitante fuera del tiempo.

Con distancia, Angélica observa a "...mujeres que agitan carnes de sobra fuera de las exiguas tiras de sus trajes de baño" (308), pero, al mismo tiempo, sus ojos "impúdicos" no pueden dejar de mirar "el torso de los jóvenes, sus anchas espaldas, los brazos y cuellos atléticos, esas cabezas juguetonas, cubiertas de arena que desordena el viento" (308). Angélica, "una mujer ya de sus años" (307), protegida del sol por una sombrilla con mango de dragón, cruza la muchedumbre fantaseando con un encuentro furtivo. Difícilmente encontraremos en Couve otra obra en que la tradición y el deseo se imbriquen tan abierta y desesperadamente: si al artista neoclásico toda la tradición le recuerda que ha llegado tarde a la hora de la historia - es necesario, por tanto, mirar hacia atrás-, no es menos cierto que el anhelo por otros cuerpos se convierte en el espacio privilegiado para dar cabida al deseo por desplazar y desfigurar la tradición. Tal sería el caso ejemplar de la mirada erótica de Ingres (Bryson 158-159). Couve, por supuesto, no solo llega tarde a la Francia de Flaubert, sino que también parece llegar tarde al balneario de Cartagena (su época de gloria, a la que pertenece Angélica Bow, se ha esfumado); y sin embargo es precisamente allí, en esa playa, en donde la herencia del pasado empieza a ofrecerse como nunca antes para ser intervenida, retocada, reescrita.

Baste con revisar los títulos que la autoría barajó para este relato: Gartagenta, Ariosto, Purgatorio, Balneario (los dos últimos no están tachados en la portadilla del cuaderno que guarda el manuscrito). Nuevamente, asombran las correspondencias internas de la obra de Couve, que la disponen como si cada texto fuera parte de un único diseño, un único relato que busca su forma, encontrándose en este opúsculo - apretado como un puño - el imaginario del litoral central que más tarde caracterizará su narrativa. Purgatorio de inmediato nos recuerda - o nos anuncia, según donde se lo mire- los guiños a la Divina Comedia que vendrán en La comedia del arte (1995) con su esquema tripartito: "Camondo en los infiernos", "Media tinta" (" ¿No es esto purgatorio? ¿Un tramo de enlace entre la sombra profunda y la luz radiante?" [378]), y "Un grito en el cielo". Purgatorio también porque Cartagena, con sus caserones de principio de siglo, parece habitada por almas en pena o presencias fantasmales de otro tiempo - como Angélica Bow-, que vagan a la espera de un encuentro, de un cuerpo que les devuelva a la vida: "Si estoy viva", piensa, "no es posible que no me ocurra nada" (308). Anotemos, al pasar, que para el lector chileno es relativamente sencillo conjeturar una de las razones de por qué Balneario no se llamó Purgatorio: ya en 1979 Raúl Zurita, en un poemario homóni- 
mo, se había atrevido a reescribir la obra de Dante sobre el paisaje nacional. Quizá a partir de este vínculo dantesco podamos comprender la admiración que Couve le profesaba a su proyecto poético, de naturaleza harto distinta al suyo (Campaña 56). Las filiaciones confesas de Couve a primera vista despistan, sí; pero, bien mirado, puede que sean menos arbitrarias de lo que parecen.

Cada título desechado en el manuscrito se ofrece como el pasadizo a un nudo ciego del relato; como un cambio de perspectiva similar al que debe adoptar el espectador de Los embajadores de Holbein para ver la calavera en la anamorfosis, la biblioteca esquiva de la que se nutre su literatura: Ariosto. Solo ahora resuena en toda su magnitud el nombre de la protagonista del relato, Angélica, y sus particulares circunstancias: "Aprieta fuerte el mango del quitasol que representa una cabeza de dragón con escamas verdes, cuyos ojos vivaces son inmunes a la resolana del día" (308). El lector recordará el famoso "Canto X" del Orlando Furioso en donde el caballero Ruggerio o Roger, volando en su hipogrifo, descubre a Angélica desnuda y prisionera, amarrada a una roca, ofrecida como víctima a un monstruo marino:
Y al mirarse desnuda
delante de Roger
celar pretende
las partes que, aunque bellas en extremo
al ojo humano la mujer no enseña;
pero amarrada a la dura peña
las manos ni encubrir pueden
su faz regada por copioso llanto [...].
Medio cuerpo en el agua y medio afuera
mayor que un buque muéstrase entre tanto
el monstruo horrible. (163-164)

Angélica prisionera al borde del mar, Angélica anquilosada a su propio purgatorio. Mientras tanto, Ariosto, el genio del Renacimiento italiano, precede el arribo de los dioses olímpicos al balneario; el desembarco de Apolo en Cartagena, un lugar perdido de la costa de Chile. Advirtamos, eso sí, que el narrador de Couve está muy lejos de retomar el enrevesado y monumental argumento del Orlando furioso en su totalidad (recordemos que este relato tiene apenas una decena de páginas). De hecho, del "Canto X" recupera apenas su tramo final: los últimos 25 versos, que corresponden al encuentro de Ruggerio con Angélica. Frente a las proporciones monumentales del Orlando furioso, Couve presenta un relato tan pequeño como una cáscara de nuez: su perfecto contrapunto. Un Orlando de bolsillo, una ironía elegante y diminuta. 
No es casual, de ninguna manera, que precisamente este mismo pasaje del Orlando haya servido también de inspiración para una célebre pintura de Ingres: Roger délivrant Angélique (1819). Así lo vemos en el manuscrito de Balneario, cuando Couve anota a la manera de título provisorio, luego tachado fuertemente: Rroger liberando a Angética (sin núm.). Porque aunque Couve coquetee en la versión preliminar con la idea de nombrar cada capítulo como un Canto, a la manera de Ariosto, lo cierto es que comienza a intervenir el Orlando justo en el punto en que Ingres lo dejó: en la pose desamparada de Angélica desnuda, la sexualidad galopante — no olvidemos la acometida violenta de la lanza - y la mirada del voyeur. ${ }^{2}$

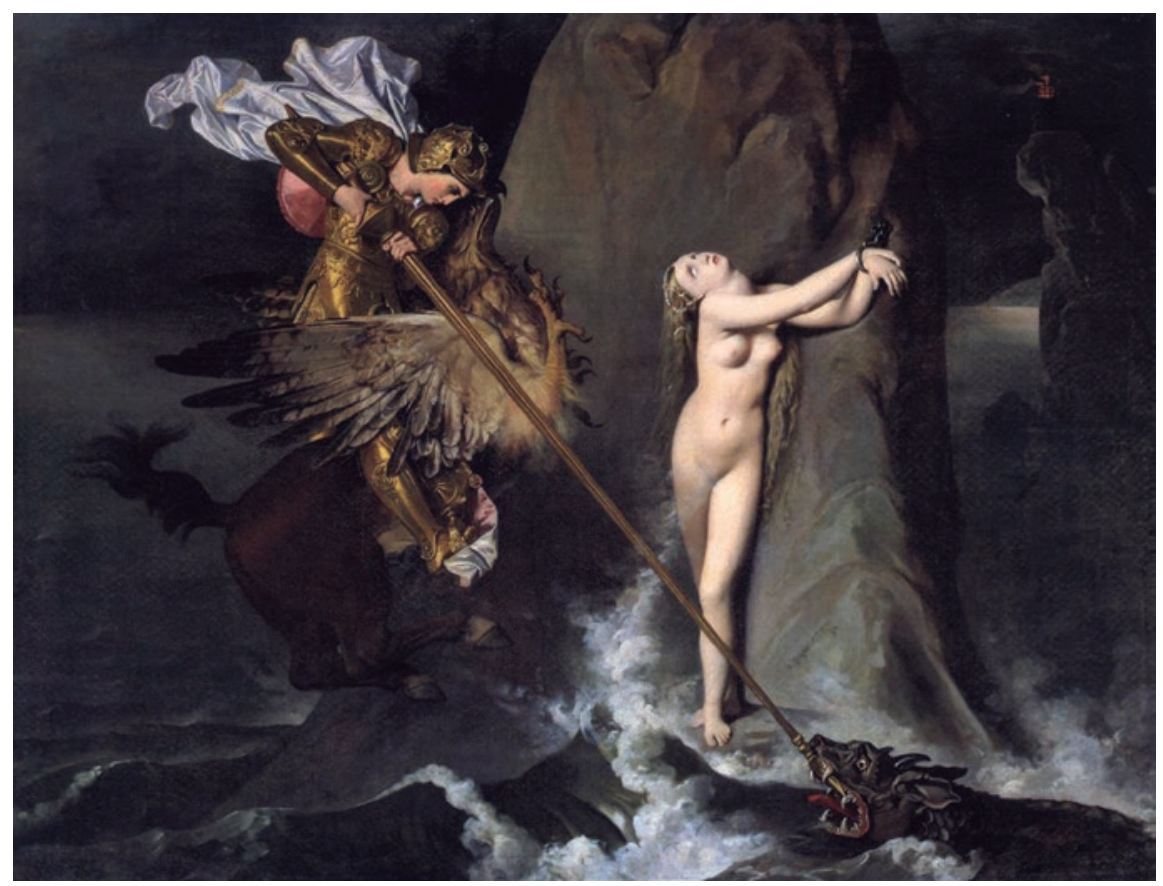

Figura 1. Roger liberando a Angélica, de J.A.D. Ingres (1818)

2 Así lo plantea Susan L. Siegfried en su sugestivo "Ingres' Reading - the undoing of narrative": "Beyond the obvious sado-masochistic overtones of the manacled female nude, there is the voyeurism involved in the exposure of Angelica's body. The painter again keyed off the poet. Ariosto lingers over the sensual description of Angelica's body, most vividly when Roger first inspects her, and the poet describes her tear-stained sobbing nakedness and futile attempts to hide her face from the scrutiny of a stranger [...]. Ingres picked up on this sadistic element in the poem by showing twistingly away from Roger only to expose herself to the viewer [...], and in the painting as in the poem the gaze travels up and down her body, against her will"' (673, énfasis nuestros). 
Diseñado como una réplica chilensis de la pintura de Ingres (y sus fuentes), el relato de Balneario se propone reescribir la escena desde coordenadas locales. En manos de Couve, la escenografía de los riscos tenebrosos en la que vemos encadenada a la joven Angélica de Ingres, se transforma en una antigua casa de veraneo al borde del mar: "[i]ncrustada en un acantilado, da la espalda al horizonte y tiene adelante un jardín que termina en una empalizada que colinda con el abismo" (309, énfasis nuestros). Así, moviéndose de término a término, esta traducción se ofrece al lector cual diccionario de correspondencias: en lugar de Angélica cautiva, desnuda y atada con cadenas, Couve propone a una mujer mayor en una prisión doméstica, pero con un cerrojo igualmente férreo: "Ya bajo llave (y con qué violencia la gira sobre la cerradura), [Angélica] se desabrocha la blusa, se quita los zapatos y se echa sobre la cama" (309). En el énfasis de la llave, resuena otro cautiverio, el de los apretados grilletes en las muñecas de la joven virginal de Ingres.

$\mathrm{Y}$ en una lección de realismo, el narrador de Couve convertirá ese grotesco monstruo mitológico, que se asoma amenazante por la esquina, en el famoso barómetro de Flaubert - para usar el ejemplo de Barthes en $\mathrm{El}$ efecto de realidad -, al presentárnoslo convertido en la terminación de una sombrilla de la protagonista: "[...] el mango del quitasol que representa una cabeza de dragón con escamas verdes, cuyos ojos vivaces son inmunes a la resolana del día" (308). Más adelante aparecerá reposando, diminuto y vigilante, sobre un mueble de la casa: "El dragón de escamas verdes y duras, con los ojos abiertos, despabilados, insomne como su dueña, parece adivinar sus pensamientos, porque la mira fijo desde la cómoda en sombras" (312).

Se contempla así la alucinación de la épica caballeresca, rebajada ahora a las formas de insignificantes objetos cotidianos, unas chucherías; transportada a otro verosímil, al reino del detalle de la descripción realista (platos, cucharas o barómetros, naturalezas muertas cuyos misterios laten en segundo plano). ${ }^{3}$ Después de todo, Couve - observador pictórico privilegiado- ha reparado en que el centro de la tela de Ingres es Angélica, y que la lucha

3 Remitimos a la visión panorámica de Reading in detail de Naomi Schor: "To say that realism, in particular French nineteenth-century realism, is a 'detailism' [...]; is to rehearse a topos which runs through all of the critical discourses on realism from Bruntiere to Barthes, from Lewes to Lukács. Whether the association is positively or negatively valorized, whether the detail is said to be in the service of a conservative or a revolutionary aesthetics, producing its mimetic effect by means of a referential emptiness or plenitude, the detail occupies — despite or perhaps because of its insignificance- a privileged position in the theory of realism" (175). 
de Roger y el monstruo es la recreación del tema de San Jorge y el dragón (Siegfried 657). De ahí que el narrador, cual filólogo de la imagen, hable específicamente del dragón (no del Orco ni del monstruo) y, todavía más, que titubee en el manuscrito al llamar a su protagonista Andrómeda - esa otra encadenada, que, junto a Perseo, es el antecedente obligado de Angélica y Roger tanto para Ariosto como para Ingres-. ${ }^{4}$

Apresurémonos, entonces, a adelantar dos observaciones: mientras el poema de Ariosto indica que el monstruo es parcialmente derrotado por el brillo del escudo de Roger (otro sol), ${ }^{5}$ nos enteramos, con sorpresa, de que este dragón resulta inmune a la resolana del día (¡él mismo es, paradójicamente, un quitasol, siempre protegido!). Especulativamente diríamos que, no por nada, Couve sitúa la escena en temporada de verano y, con astucia, sustituye al efebo de broncínea armadura por unos muchachos broncéandose en la playa. ¿Se reflejarán allí también, en esos torsos, los rayos de luz que liberarán a nuestra marchita Angélica de su oscuridad? En ese caso, si una de las claves de la pintura de Ingres consistía en la mirada masculina - vestidasobre el desnudo femenino, la escena de la playa de Balneario invierte los papeles, al desvestir a los muchachos de su armadura - al menos los deja en pantalón de baño - y convertir el deseo de Angélica en el verdadero protagonista de la escena: "esos cuerpos ágiles, desnudos..." (310).

Aunque, en contraste con estos cuerpos iluminados de golpe, está el cielo nocturno del cuadro, la "cómoda en sombras" desde donde el otro dragón, la miniatura, mira sin apenas ser visto (evocación del monstruo de Ingres que se asoma ligeramente, como una pura insinuación o latencia). Angélica paseándose en la playa a pleno sol; Angélica en la penumbra fantaseando con su liberación, es un claroscuro en el que no sabemos si nos encontramos de día o de noche, a la manera de La ronda nocturna (1642) de Rembrandt - pintura sobre la que Couve volverá una y otra vez en su narrativa y en sus escritos sobre

Así lo señala la crítica, vox populi: “Ever since the 'Orlando Furioso' first appeared readers have recognized that Ruggiero's rescue of the bound Angelica from the Orca, monster of the sea [...] is modeled on Perseus' rescue of Andromeda in Ovid's 'Metamorphoses" (Javitch, "Rescuing Ovid from the Allegorizers" 97); "In ['Orlando Furioso'] the rescue of Angelica from the seamonster is inspired by the tale of Perseus and Andromeda in Ovid's 'Metamorphoses': indeed, Ingres's picture of the episode emphasizes the similarity" (Highet 153-154, énfasis nuestros).

5 Leemos en el Orlando furioso: "Colocándose [Roger] enfrente de la fiera,/ del mágico broquel levanta el velo./ Semejante al del cielo,/ aparece otro sol. Despavorido,/ cual el pez en la cal, el monstruo queda/ privado de sentido/y, por las olas de la mar lanzado,/ inmóvil va del uno al otro lado" (Ariosto 165). 
arte- Canto primero, así subtitulaba Couve los primeros pasajes del manuscrito, pero también esbozaba llamarlos Ronda primera. Sospechamos que, siguiendo a Rembrandt, otro modelo, otro maestro, Couve cifra los ritmos del relato en estas formas eruditas de estructuración narrativa, reelaborando - una referencia tras otra, un pliegue tras otro - un panteón sincrético. ¿ $\mathrm{i}$ No son verdaderas rondas las vueltas que da Angélica por el balneario; la espera de una cacería amorosa (“"[m]añana, a esa misma hora, volvería hasta el paseo ante las olas..." [308])? Pero precisemos: es La ronda nocturna, tomada en su sentido más literal y erótico, reinterpretada desde el ardor del verano como cruising (" ${ }^{6} \mathrm{i}$ si salgo de noche? En ella todos los gatos son negros..." [312]). ${ }^{6}$ Cruising, así navega Angélica Bow entre el populacho que "la desviste" (312), ella misma un verdadero mascarón de proa (en inglés bow, su apellido) que, erotizado, va por la costanera "contra la corriente" (313).

Pero quizá la traducción más radical de Balneario tenga relación con esa escenografía contra la que veíamos recortarse los personajes de Ingres, y que Couve - en un magnífico salto de asociación libre - se encarga de superponer al paisaje de Cartagena, específicamente a las vistas de sus riscos escarpados y roqueríos (¿los de la playa chica o la caleta San Pedro?). La Isla del Llanto ("[a]pellidada así con razón" [Ariosto 162]) y la popular Cartagena: en estos inesperados maridajes de referencias, hay algo de esfuerzo olímpico por unir dos mundos bifrontes que se repelen; la búsqueda de una mínima síntesis para un clasicismo criollo. Lejos de un capricho, la conexión surge del redescubrimiento de la geografía local a la luz de la tradición (estos roqueríos y acantilados también reclaman su Ingres) y viceversa (como los hijos de los inmigrantes de antaño, vuelven a escenificar el mito y transfiguran la pinacoteca de sus mayores en otras tierras). Yuxtaponiendo ambos escenarios, cuya afinidad visual Couve señala con el dedo como una zona de contacto, no podemos dejar de preguntarnos si este apunte paisajístico no corresponde acaso a la viga maestra que permite el trasvasije referencial. ¿Será esto lo que Couve ha venido a llamar "la profunda experiencia americana" de la que el museo europeo saldría enriquecido ("Prólogo" 10)?

6 Versión erotizada del flâneur, así lo interpreta Mark Turner: "The streets and other public spaces remain open to different kinds of users and to many kinds of overlapping social practices. The reciprocal, erotically charged gaze is still a significant way of making contact with others and of experiencing the city. The cruiser, like the 'flâneur', continues to rely on the ambiguities of urban modernity, on the uncertainties that linger in the fleeting experience of a backward glance" (66), y en otro lugar: "The cruiser's intention is to find in the passing glances in the streets that person whose gaze returns and validates his own $[\ldots]$. It is the sexualization of the city of modernity that not only allows for but also necessitates ways of interacting that are based on desire" (59). 


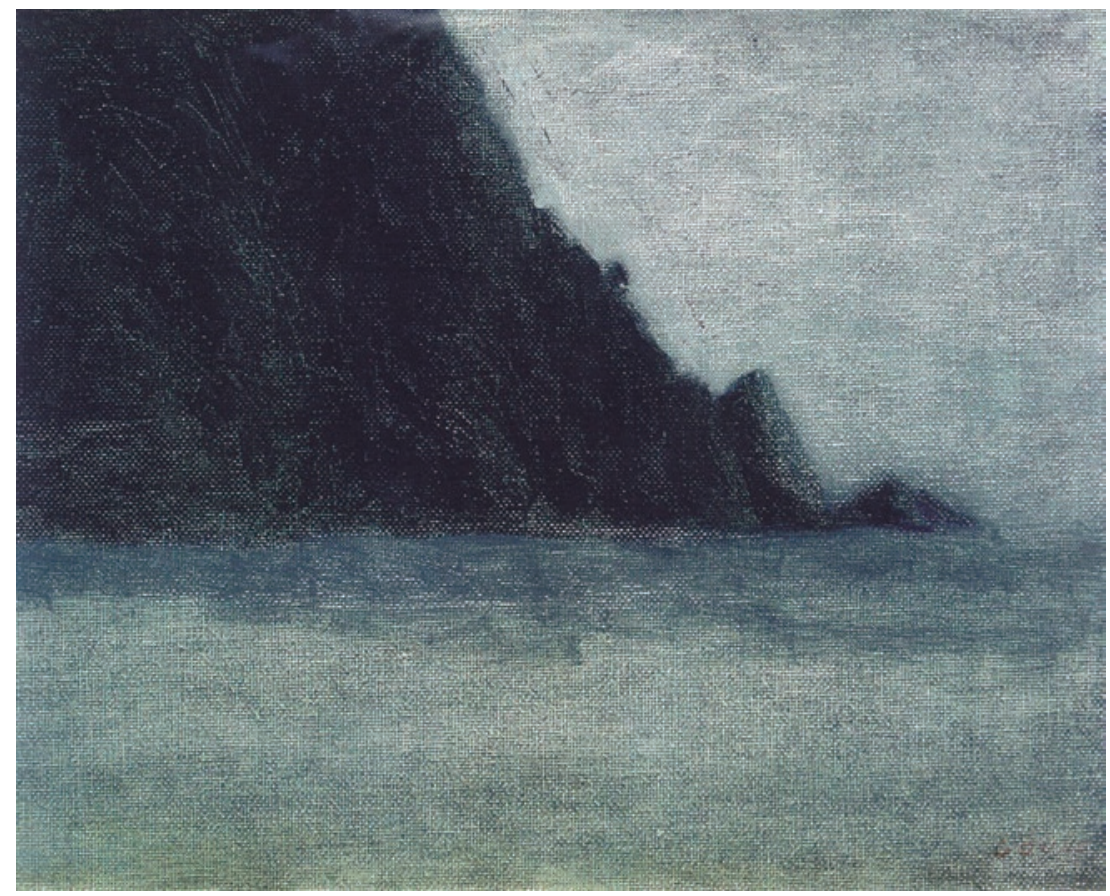

Figura 2. Paisaje costero (c.1988), de Adolfo Couve (en Campaña 209): visión de los roqueríos de Cartagena pintada alrededor de las fechas de la escritura de Balneario

Experiencia americana, de acuerdo, pero en la que todo se ve maliciosamente trastocado, porque Ingres ha venido a naufragar a Cartagena, traído quizá en un viejo baúl. Como ya habrá podido sospechar el lector, en la recreación de Couve cada cita de la tradición aparece invertida, partiendo de su transgresión más evidente: ante el desnudo venusino de la pintura de Angélica, Balneario goza con la minuciosa exhibición de esa Angélica ahora decrépita (este es su triste presente). Un cuerpo degradado, esperpéntico, en donde lo clásico contempla su propia caducidad en el reflejo de Cartagena $^{7}$ - ambas atrapadas en el recuerdo de tiempos mejores, anudadas para siempre en un destino compartido-:

7 Entre nosotros ha sido el crítico Leonidas Morales - en un seminario monográfico de postgrado dicado en la Universidad de Chile (2011) - el primero en advertir la afinidad que hay entre las imágenes ruinosas de Cartagena representadas por Couve y la noción de alegoría propuesta por Walter Benjamin — que se nutre, precisamente, de la caída y 
Entonces se incorpora y enfrenta al espejo del ropero [...], y atreviéndose se baja los tirantes, y desnuda hasta la cintura recorre sus pechos flácidos, su vientre hecho una arruga, sus antiguas formas desdibujadas. $\mathrm{Y}$ al intentar alzar esos senos a su ubicación precisa, deja caer el resto de la enagua que cubre sus pies. Allí aparece enteramente desnuda, protegida por ese calzoncito que no es capaz de quitarse.

Un cuerpo devastado como por un escultor poco cuidadoso, y atrás el esplendor del océano y el cielo, masa que recorta esa silueta de piernas flacas y pelo teñido (309-310, énfasis nuestros).

Estamos ante la nostalgia de Ingres ("sus formas antiguas desdibujadas"), fallido tableaux vivant frente al espejo (Balneario es, justamente, un espejo deforme de citas en que Ingres se mira y no se reconoce) y, por cierto, la parodia $^{8}$ destructiva de cualquier equivalencia clásica. Porque Couve escribe su relato con Roger liberando a Angélica en una mano y con el Canto $\mathrm{X}$ de Ariosto en la otra. Y si en el Orlando furioso leemos de Angélica que "[l]inda estatua del mármol más precioso, / a la peña sujeta/, por pintor industrioso/ Roger creyera ver si gota a gota/ por su seno correr no viera el lloro" (163, énfasis nuestro), Couve reescribe el pasaje al pie de la letra, pero desfigurándolo deliberadamente: “[u]n cuerpo devastado como por un escultor poco cuidadoso". No en vano hablábamos al comienzo de anamorfosis ${ }^{9}$-el medallón oblicuo a los pies de los embajadores-cuando nos referíamos a las

caducidad de lo "clásico"-. Morales, además, dicta periódicamente en la Universidad de Chile el único curso dedicado exclusivamente al estudio académico de la obra literaria de Adolfo Couve del que tengamos noticia.

8 No en el sentido convencional del término, sino en la definición bajtiniana, que lejos de estar circunscrita completamente en el humor, se estructura a partir de la declaración de guerra de dos voces: "Here, as in stylization, the author speaks in someone else's discourse, but in contrast to stylization parody introduces into that discourse a semantic intention that is directly opposed to the original one. The second voice, once having made its home in the other's discourse, clashes hostilely with its primordial host and forces him to serve directly opposing aims. Discourse becomes an arena of battle between two voices" (193).

9 Lacan en su Seminario XI formulaba una suerte de chiste libertino para ejemplificar la anamorfosis y sus particulares procedimientos (deformar una imagen al disponerla sobre otra superficie), que como chiste libertino debe permanecer en francés: "Comment se fait-il que personne n'ait jamais songé à y évoquer... l'effet d'une érection? Imaginez un tatouage tracé sur l'organe ad hoc a l'état de repos, et prenant dans un autre état sa forme, si j'ose dire, développée" (82). Después de todo, esta singular anamorfosis que es Balneario, se encuentra tensionada por el erotismo más desesperado: "Por eso prefiero el rompeolas, ahí no se conoce 
influencias confesas de nuestro autor: como en ese juego de perspectiva, aquí vemos a Ingres y su biblioteca, pero con "sus antiguas formas desdibujadas" al ser reacomodados sus puntos de referencia sobre una nueva superficie ("la profunda experiencia americana").

Experiencia americana que - explicitemos - para Couve no está desprovista de un sesgo de clase: sacar a Ingres del Louvre para llevarlo a un balneario plebeyo ("[e]n medio de los quioscos improvisados y las basuras" [308]) es también un modo de escandalizarlo, de hacerlo caer, de colisionar lo alto y lo bajo. En suma, de dejar que el gran pintor aristocrático se pierda en la marea del populacho (¿ingres en Cartagena, Couve en Cartagena?). Un sabroso detalle ilustra el caso: mientras Angélica Bow rememora patéticamente la pose desnuda de su precursora, el narrador describe la música que resuena en su habitación: "Entonces una profunda voz varonil le canta la canción de la temporada, le habla de adorarla $[\ldots]$, y un saxo quejumbroso corrobora los requiebros del cantante [...] [:] 'Y te voy a adorar esta vez como nunca has sentido, porque soy y seré el que más te ha querido', y el saxo otra vez llama a su corazón..." (308). La canción que tararea el narrador de Couve no es, por cierto, de su propia industria, ¿la recordará el lector con buen oído? Se trata de El que más te ha querido (1989), de Dyango, éxito radial que nos invita a leer Balneario con música de fondo de Cartagena y, además, a fechar su composición ("la canción de la temporada"). Pero, por sobre todo, nos ofrece un Couve cebolla, ${ }^{10}$ o más bien, uno que juega a serlo; y, de paso, un Ingres y Ariosto en versión cebolla, al borde del camp y el kitsch local. No podemos dejar de pensar, por oposición, en las adaptaciones a la ópera del Orlando furioso: Vivaldi, Handel, Haydn —a los que Angélica debió haber escuchado en otro tiempo-, se abrazan ahora con Dyango, en una muestra más del tropo de contrastes brutales; la coquetería de polos opuestos del humor literario de Couve. Humor, dicho sea de paso, de raíces cervantinas, si recordamos el diálogo de don Quijote y el barbero que abre la segunda parte: "Dígame, señor don Quijote, [... ¿ ¿no ha habido algún poeta que haya hecho una sátira a esa señora Angélica [...]? Bien creo yo, dijo don Quijote, que si

a nadie, y como a Araneda lo devuelvo a casa, es posible que una de estas tardes, un bañista encantador me proponga llevarme a una de las residenciales de la playa grande" (311).

10 Con el término cebolla recurrimos deliberadamente aquí a un chilenismo, definido por el Diccionario de uso del español de Chile como: "Adj. Excesivamente sentimental. Espon. Desp. '¿Acaso no han escuchado música cebolla? Más de alguno habrá soltado una lágrima escuchando las terribles letras de las baladas te amo, te odio, me dejaste, me abandonaste, etc."' (189). 
Sacripante o Roldán fueran poetas, ya me hubieran jabonado a la doncella; [...] pero hasta ahora no ha llegado a mí noticia de ningún verso infamatorio contra la señora Angélica" (Cervantes 559-560).

Ariosto, Ingres, Couve, en ese orden. Apuntemos que si para el lector del Orlando furioso, Angélica se ofrecía como una visión ecfrástica cuya promesa le corresponderá a Ingres materializar siglos más tarde ("estatua del mármol más precioso... por pintor industrioso"), Couve - en la fantasía de Balnerario - pareciera presentarse ante nosotros como quien viene a cerrar el círculo; a devolver la pintura de Ingres a su lugar de origen. De la escritura (Ariosto) a la pintura (Ingres) y, finalmente, de regreso a la escritura (Couve): viaje de ida y vuelta en el que también resuena la fantasía del escritor chileno de ser traducido al francés (Francia, Chile, Francia), con la salvedad de que en este ejercicio Couve aparece convertido en el Ariosto americano. ¿Ariosto Couve, Adolfo Couve? Por lo visto, no solo Angélica se mira en el espejo de Balneario (¿tendremos que recordar ese óleo de Tiziano (1510) largamente considerado como retrato de un barbado Ariosto, en el que de pronto, fantasmalmente, nos resulta tan fácil imaginar al propio Couve imitando su pose?). Ariosto rezaba el título tentativo de Balneario, y de haber continuado así habríamos tenido otra A mayúscula más en donde podría espejearse el nombre de Adolfo en su narrativa, junto a Alamiro, Angelino, Anselmo, Augusto y, por supuesto, Angélica Bow (Valdés 10).

Ahora bien, ¿dónde está Roger, el caballero Ruggerio, para rescatar a nuestra Angélica? Aunque aquellos torsos bronceados de los muchachos ("otro sol") nos entregaban la expectativa de su brillante armadura, todavía no lo reconocemos de cuerpo entero, individualizado, con la claridad que han cobrado otros elementos de la pintura de Ingres (e.g. los acantilados, los grilletes, el dragón, Angélica desnuda). ¿Es que brilla por su ausencia? En parte sí, pero primero lo veremos encarnado - no podía ser de otro modoen un "fornido gásfiter" (311) (otra parodia):

Repasa el día, cavila el asunto de la llave que goteaba en el lavamanos del baño esa mañana, piensa en el joven que vino a repararla. En ese olor penetrante a transpiración, y lo que éste insinuó cuando manipulaba la llave inglesa:

-Yo le hago a todo... ¿ entiende, señora?... Por una camiseta, por lo que sea. Angélica, enmarcada en el vano de la puerta, desoyó esas recomendaciones por considerarlas impropias, aunque después de todo se avenían a su búsqueda diaria frente al rompeolas. ¿Qué la detuvo entonces? ${ }_{\mathrm{i}} \mathrm{Pudor}$ a 
develar el derrumbe de su cuerpo? ¿La violencia de la situación de quedar a merced de un mocetón del que ni siquiera conocía el nombre? (311).

La llave goteando, el gásfiter sudoroso, la propuesta indecorosa remedando los giros del habla popular (señora, yo le hago a todo): el relato de Couve, reconozcámoslo, saluda desde la tradición neoclásica los motivos del guión porno; la conocida fantasía erótica burguesa de un encuentro liberador con las capas bajas, encarnada desde principios de siglo por desinhibidos mocetones y obreros sin nombre. ${ }^{11} \mathrm{Y}$ digamos de paso que al dejar innominado al caballero Ruggerio, nos invita a llamarlo ahora Rogelio, nombre ya no tan prestigioso con el que Couve, por lo demás, bautizó al niño huérfano del relato El pasaje (1989), al describir por única vez el paisaje de la pobreza santiaguina. Después de todo, ¿no serán ellos los que vienen a rescatar, durante su ruidoso verano, a Cartagena de su melancólico abandono de invierno, trayendo consigo la posibilidad de liberarla por fin del recuerdo anquilosado de su época elegante? Y anotemos que la anécdota veraniega de Balneario aparece estructurada como un paréntesis entre dos inviernos. Invierno, verano, invierno: ¿otro claroscuro con la luz estival al centro de la composición?

Texto minúsculo, escrito con pinzas: como si la repetición buscara llamar nuestra atención, dos veces en el mismo párrafo se nos menciona la palabra "llave" (lavamanos, herramienta), que como el dragón de Ingres se multiplica en distintos objetos a su paso, y nos envía - por desplazamientoa esa otra llave que mantenía a Angélica prisionera ("Su casa de veraneo es enorme, tanto así que posee un ala completa bajo llave" [308, énfasis nuestros]; "Ya bajo llave (y con qué violencia la gira sobre la cerradura)..." [309, énfasis nuestros]). Tirando un poco más del hilo, no deja de ser cierto — desde la ley de valores del relato- que para liberarla de esos grilletes, Ruggerio debió hacer las veces de maestro chasquilla, no muy lejos de convertirse su lanza

11 Así lo describe Florence Tamagne para el ámbito europeo de inicios del siglo XX: "It was a kind of fetishism; the working boy, or one engaged in manual labor, was endowed with an intense erotic charge. This is striking, for example, in Marcel Jouhandeau's 'Memorial IV' $[\ldots]$ where he evokes the tensions of his youth in the company of the butcher's assistant and apprentices who worked in his father's shop. Similarly, Christopher Isherwood suffered from an inhibition, which was the not uncommon among higher class homosexuals; he could not find a sexual release with a member of his own class or from his country. He needed a foreigner from the working class" (262). En cuanto a la interpretación en clave queer de la obra de Couve, remitimos al artículo recientemente publicado de Bernard Schulz-Cruz: "El claroscuro homosexual en El picadero, de Adolfo Couve" (2016). 
en una pedestre "llave inglesa". Y cuánto podrá enseñarnos aquí la poesía erótica medieval, que tanto sabe de llaves y cerraduras. Pero, ¿no es también Angélica Bow - por su apellido anglosajón- esa llave inglesa que se sueña manipulada en manos del "fornido gásfiter"?

Sea como sea, no es inmotivado el gesto de situar a Roger y Angélica en el arrebato del sexo casual; en una transacción que bordea "la violencia" y que supone "quedar a merced". Mal que mal, el mismo poema de Ariosto relata que el caballero, luego de rescatar a la joven virgen, intenta tomarla por la fuerza ("Rara vez la razón, rara refrena/ la ardiente furia de un amor lascivo/ ante la imagen del placer [...]./ ‘ ¿Es este, es este el galardón, ingrata,/ que a mis servicios das? ¿Por qué con arte/ tu perfidia, mal grado, me arrebata/ lo que yo nunca me negara a darte?" [167-168]); y la autoría de Balneario se encargará de buscar afinidades iconológicas que refuercen esa fantasía de erotismo y violencia: "—Qué tal, ¿cómo te llamas? —-Sabina An= gélica Andrómeda [finalmente, en la versión publicada, Angélica responderá: -Cartagena]" (Manuscrito de Balneario, sin núm.). ${ }^{12}$ Leído en clave erótica, La vida secreta de un pintor neoclásico - ese título que Couve alguna vez barajó para su novela La lección de pintura - también puede venir a significar aquí la posibilidad de cifrar el deseo en la cita pictórica; la erudición artística como contraseña amorosa: decir Me llamo Sabina equivale a enunciar la fantasía silenciosamente; a decirlo todo sin salir del Museo (quiero ser raptada), tal como La ronda nocturna venía a escenificar el cruising de la mano de Rembrandt. La vida secreta de un pintor neoclásico: por simple asociación, recordemos el frenético movimiento de los cuerpos de la escultura de Giambologna en Florencia, El rapto de las sabinas (1583), o más cerca de Ingres, La intervención de las sabinas (1799), de Jean Louis David ("testimonios convincentes como el de David o Ingres..." [Couve, "Prólogo" 8]).

El relato de Couve, sin embargo, borra sus propias huellas o, si se quiere, borra con el codo lo que escribe con la mano. Solo permanece la imagen deforme de la anamorfosis, el puño apretado de la miniatura, la lejana evocación de

12 Para los lectores que vendrán, transcribimos del manuscrito la versión previa de este diálogo fantaseado por Angélica, el coqueteo con un desconocido imaginado en el rompeolas (lugar que Couve en un óleo de 1984 pinta abandonado [Campaña 194]). Más extenso que en relato editado, da cuenta de la imitación aristocrática de los giros populares por parte del narrador: "-Qué tal, ¿cómo te llamas? - Sabina Angélica Andrómeda - ¿Sola? - ¿Te sirves un refresco? - Encantada $-{ }_{\mathrm{C}}$ Paseando? - Sí - ${ }_{\mathrm{C}}$ Soltera? -Sí - Vives cerca, tienes casa por aquí. -No, he venido por el día. - ¿ $Y$ Y no te bañas? - Me lo prohíben los médicos" (sin núm.). 
Ingres apenas sugerida a posteriori por el deambular de una vieja Angélica con su sombrilla de dragón - el eco de la pinacoteca fue ahogado antes de resonar en la superficie, triturado por el dragón de la corrección-. Con todo, si para Jean Bellemin-Nöel, la lectura de un manuscrito consistía en confrontar un texto con su propia alteridad, con su infancia obliterada (32), Couve en estos papeles donados a la Biblioteca Nacional poco antes de su muerte, cual testamento, nos lega una serie paralela a la de su obra Cuarteto de la infancia: otra fantasía de los orígenes, ya no del artista encarnado en esos niños aristocráticos, sino de la obra, en papeles atesorados como la niña de sus ojos: "originales (cuídenlos)", dicen los cuadernos de El picadero (sin núm.).

A estas alturas, el lector podría estar preguntándose por qué entonces Balneario no se tituló Roger liberando a Angélica. La respuesta resulta desasosegante por lo sencilla: en Balneario, Roger no libera a Angélica (ella se resiste o no se atreve a ser liberada). La autoría "corrige" el desenlace de Ariosto e Ingres, frustrándolo, y dejando para siempre a Angélica cautiva del dragón. Es así como Couve reescribe la herencia del Orlando furioso desde la negatividad, al mismo tiempo que repara la ausencia que denunciaba don Quijote. Por lo demás, no es un mero decir cuando señalamos que el narrador "corrigió" el desenlace: porque hubo otro, mucho más luminoso, que se perfilaba como un Capítulo segundo de un relato que quizá esperaba alcanzar la extensión de una nouvelle y que, sin embargo, quedó en los pliegues del manuscrito, otra cárcel. Transcribimos íntegramente ese fragmento inédito que está al final del mismo cuaderno que guarda el manuscrito de Balneario:

\section{La escena del jardín}

Una mañana tarde del mes de febrero le cambió finalmente la vida. Imposibilitada de acudir al rompeolas como era su costumbre, debido a que tenía gente a la hora del té, resolvió permanecer en la terraza que había a un costado de su extenso jardín. Premunida de su quitasol, una silla plegable y una novela, se instaló allá intentando imbuirse en los sucesos de la trama para reemplazar esa aspiración tan vaga y al mismo tiempo tan irrenunciable te pasearse como aguardando algo, que la hacía pasearse a lo largo del rompeolas playa bajo el intenso sol, como esperando a alguien, algo.

El libro versaba sobre un suceso obviamente amoroso, una pasión immposible, de dudosa verosimilitud que de todos modos se dejaba leer. El quitasol se le desviaba de su posición a causa del interés que en Angélica Ursula suscitaban esos acontecimientos. Y hasta en cierta ocasión lo 
dejó caer siendo empujado suavemente por la brisa, acompañado por su tumbona. Este llegó hasta el límite de esa terraza llevada sobre el mira... (Manuscrito de Balneario sin núm.).

Escena del jardín llena de augurios ("le cambió finalmente la vida"); incluso vemos el quitasol - es decir, el dragón - a punto de perderse por el acantilado: ¿llegará, por fin, Ruggerio? No lo sabemos, el manuscrito termina allí y sus páginas siguientes están arrancadas, como si el relato hubiera tanteado la idea de escapar más allá de la frontera impuesta por Ingres (el marco del Canto X de Ariosto), para luego arrepentirse y regresar a los límites seguros de la pintura del maestro (¿ilos grilletes de Angélica?). Y es que este comienzo de capítulo desechado era un atisbo de libertad y de aire fresco, no conseguido a través de Roger (el gásfiter ya ha sido descartado), sino a través del placer compensatorio de la lectura ("[i]ntentando imbuirse en los sucesos de la trama para reemplazar esa aspiración [...] que la hacía pasearse a lo largo del rompeolas"). Otro rescate, sin duda, y de pronto nos parece ver que, disfrazado en ese libro en manos de Angélica, está el mismísimo Orlando furioso con sus galimatías argumentales, la fabulación sin límites de Ariosto, lo inverosímil de la trama (“[...] un suceso obviamente amoroso, una pasión [...] de dudosa verosimilitud").

Sin embargo, finalmente esta escena de plenitud literaria - el goce del lector que disipa los monstruos y el del narrador que se escapa de su propio pie forzado- quedará trunca, a imagen y semejanza del flirteo de Angélica Bow con el gásfiter, que es saboteado en el último instante (ella escoge seguir prisionera; enunciado y enunciación se espejean en el destino del relato). "¿Qué la detuvo entonces?", se preguntaba el narrador, y ahora también nos preguntamos nosotros. Leyes paradójicas del deseo, suponemos, lo que Renate Salecl, con ayuda de Edith Wharton y el psicoanálisis, condensó como sólo renunciando a ti puedo amarte (Salecl 25). Couve vuelve sobre sus pasos, retrotrae el final a la secuencia inmediatamente anterior al pasaje inédito titulado La escena del jardín. En un nuevo claroscuro, reemplaza el sol de la tarde por un final lúgubre, nocturno, que recuerda el cielo encapotado del cuadro de Ingres. Allí vemos - por última vez- a Angélica, que se pasea y contempla el señorío del dragón, convertido ahora en un inmenso juego de feria; en un carrusel que va devorando a la muchedumbre bajo las luces de una rueda de Chicago: "Y la Cuncuna, que al subir su lomo con la capucha de lona encierra ese griterío, y sube y baja desarticulándose" (312). Cartagena de noche, aunque vemos a Angélica iluminada en su ronda, parece que finalmente no le cambió la vida. 


\section{Obras citadas}

Ariosto, Ludovico. Orlando furioso. Tomo I. Trad. Augusto de Burgos. París: Librería de Rosa, 1850. Impreso.

Bakhtin, Mikhail. Problems of Dostoevsky's poetics. Trad. Caryl Emerson. Minneapolis: University of Minnesota Press, 1984. Impreso.

Baudelaire, Charles. "Salon de 1846". CEuvres complètes II. Curiosités esthétiques.

París: Michel Lévy Frères Libraires Editeurs, 1873. 77-198. Impreso.

Bellemin-Nöel, Jean. "Psychoanalytic reading and the avant-textes". Trad.Jed

Deppman. Genetic criticism: texts and avant-textes. Ed.Jed Deppman et al.

Philadelphia: University of Pennsylvania Press, 2004. 28-35. Impreso.

Bryson, Norman. Tradición y deseo. De David a Delacroix. Trad.

Alfredo Brotons. Madrid: Akal, 2002. Impreso.

Campaña, Claudia. Adolfo Couve: una lección de pintura. Edición revisada. Santiago: Ediciones Metales Pesados, 2015. Impreso.

"Cebolla". Diccionario de uso del español de Chile (DUECh). 2010. Impreso.

Cervantes, Miguel de. Don Quijote de la Mancha. Ed. Francisco

Rico. Madrid: Alfaguara, 2007. Impreso.

Couve, Adolfo. "Balneario". Manuscrito. Biblioteca Nacional. http://www. bncatalogo.cl/escritor/AE0022820.pdf. Web. 15 de junio de 2014.

Couve, Adolfo. "Balneario". Narrativa completa. Santiago:

Seix Barral, 2003. 307-313. Impreso.

Couve, Adolfo. "Cuando pienso en mi falta de cabeza (La segunda comedia)".

Narrativa completa. Santiago: Seix Barral, 2003. 433-477. Impreso.

Couve, Adolfo. "La Comedia del Arte". Narrativa completa.

Santiago: Seix Barral, 2003. 361-432. Impreso.

Couve, Adolfo. "La copia de yeso". Manuscrito. Biblioteca Nacional. http:// www.bncatalogo.cl/escritor/AE0022836.pdf. Web. 15 de junio de 2014.

Couve, Adolfo. "La copia de yeso". Narrativa completa.

Santiago: Seix Barral, 2003. 253-281. Impreso.

Couve, Adolfo. Paisaje costero. C. 1988. Óleo sobre cartón entelado. Colección particular. Adolfo Couve: una lección de pintura. Edición revisada. Ed.

Claudia Campaña. Santiago: Ediciones Metales Pesados, 2015. Impreso.

Couve, Adolfo. "Prólogo". Cuarteto de la infancia. Buenos

Aires: Seix Barral, 1996. 7-10. Impreso.

Dorfman, Ariel. "Apuntes para dos cuentos de Adolfo Couve para el taller de escritores de la Universidad Católica". Moros en la costa. Buenos Aires: Editorial Sudamericana, 1973. 85-87. Impreso. 
Greve, Ernesto. Historia de la ingeniería en Chile. Tomo III.

Santiago: Imprenta Universitaria, 1938. Impreso.

Higuet, Gilbert. The Classical Tradition. Greek and Roman Influences on

Western Literature. Oxford: Oxford University Press, 1978. Impreso.

Ingres, Jean-Auguste Dominique. Roger délivrant Angélique. 1818. Óleo

sobre tela. Museo del Louvre, París. https://www.wga.hu/art/i/

ingres/o6ingres.jpg. Web Gallery of Art. 14 de diciembre de 2014 .

Javitch, Daniel. "Rescuing Ovid from the Allegorizers".

Comparative Literature 2 (1978): 97-107. Impreso.

Krieger, Murray. Ekphrasis: the illusion of the natural sign. Baltimore:

The Johns Hopkins University Press, 1992. Impreso.

Lacan, Jacques. Les quatre concepts fondamentaux de la psychanalyse

(1964). Séminaire XI. París: Editions du Seuil, 1973. Impreso.

Roquebert, Anne. "A Widening Circle: Vollard and his Clients". Cézanne to

Picasso: Ambroise Vollard, Patron of the Avant-Garde. Ed. Rebecca A.

Rabinow. New York: Metropolitan Museum of Art, 2006. 218-23o. Impreso.

Salecl, Renate. (Per)Versions of Love and Hate. New York: Verso, 2000. Impreso.

Schor, Naomi. Reading in detail: aesthetics and the feminine.

London: Methuen \& Co., 1987. Impreso.

Schulz-Cruz, Bernard. "El claroscuro homosexual en El picadero, de

Adolfo Couve". Revista nomadías 21 (2016): 155-173. Impreso.

Siegfried, Susan L. "Ingres' Reading - the undoing of narrative".

Art History 23.5 (2000): 654-680. Impreso.

Tamagne, Florence. A History of Homosexuality in Europe.

Vol. II. New York: Algora, 2004. Impreso.

Turner, Mark. Backward Glances: Cruising the Queer Streets of New

York and London. London: Reaktion Books, 2003. Impreso.

Valdés, Adriana. "Adolfo Couve, narrador de lo inquietante". Narrativa

completa. De Adolfo Couve. Santiago: Seix Barral, 2003. 7-14. Impreso.

Valdés, Adriana. "Prólogo". Cuando pienso en mi falta de cabeza. De

Adolfo Couve. Santiago: Seix Barral, 2000. 7-29. Impreso. 